\title{
Sex-dependent differences in avian malaria prevalence and consequences of infections on nestling growth and adult condition in the Tawny pipit, Anthus campestris
}

\author{
María Calero-Riestra and Jesus T. García*
}

\begin{abstract}
Background: Parasites play pivotal roles in host population dynamics and can have strong ecological impacts on hosts. Knowledge of the effects of parasites on hosts is often limited by the general observation of a fraction of individuals (mostly adults) within a population. The aim of this study was to assess the prevalence of malaria parasites in adult ( $\geq 1$ year old) and nestling (7-11 day old) Tawny pipits Anthus campestris, to evaluate the influence of the host sex on parasite prevalence in both groups of age, and explore the association between infections and body condition (adults) and growth (nestlings).
\end{abstract}

Methods: Two hundred Tawny pipits (105 adults and 95 nestlings) from one Spanish population were screened for avian malaria parasites (Haemoproteus and Plasmodium) using the polymerase chain reaction (PCR)-based methods. Body condition (body mass against a linear measure of size) was measured in adults and growth rate (daily mass gain) was calculated for nestlings.

Results: The overall prevalence of infection was $46 \%$. Sixteen different mitochondrial cytochrome $b$ haplotypes of Plasmodium spp. and one Haemoproteus spp. haplotype were found. Malaria parasites were equally prevalent in nestlings and adults ( 45 and $46 \%$, respectively). Males were more likely to be infected by parasites than females, and this sex-bias parasitism was evident in both adults and nestlings. Furthermore, a lower daily mass gain during nestling growth in males than in females following infections were found, whereas the effect of infections on body condition of adults was detrimental for females but not for males.

Conclusions: Age-specific differences in physiological trade-offs and ecological factors, such as nest predation would explain, at least in part, the observed host sex and age-related patterns in Tawny pipits.

Keywords: Avian malaria, Haemoproteus, Plasmodium, Tawny pipit, Anthus campestris, Infection, Host age, Host sex, Nestling growth, Nest predation

\section{Background}

Theoretical and empirical work on a variety of hostparasite systems has demonstrated the central role that parasites play in many important aspects of host biology [1]. Prevalence of arthropod-borne parasites in wild animal populations reflects a balance between the exposure

*Correspondence: jtgarcia@irec.csic.es

Instituto de Investigación en Recursos Cinegéticos (IREC), CSIC-UCLMJCCM, Ronda de Toledo s/n, 13071 Ciudad Real, Spain of hosts to the infective stages of a parasite, and the success of the parasite in infecting the hosts [2]. This balance between host exposure and parasite success is partially influenced by the immunological capability of the host, which is known to be sensitive to traits such as sex, age, physiology, body condition and reproductive effort [37]. Avian malaria parasites of genera Plasmodium and Haemoproteus are blood parasites that occur regularly in wild populations and are one of the most popular model systems for studying host-parasite co-evolution [5, 8]. 
This type of parasites had attracted considerable attention as disease causes a variety of adverse effects on hosts [9-17], including the extinction of naive host populations [18]. Although the infections caused by these parasites can also persist in hosts for years causing no direct effects or only mild effects on fitness [9, 12, 19-21], recent studies have revealed that long-term chronic infections can produce important hidden costs for hosts [17].

The vast majority of studies exploring malaria impacts on wild avian hosts have been focused on adults, which inevitably restrict the ability to understand properly the consequences of infections for hosts. For example, during the acute phase of malaria infection many individuals were naturally removed from the population by dying [21], which makes really difficult to assess what type of parasites are involved and the real damage they caused at the population level. In this context, one interesting approach is to use nestlings as research focus. Newborns represent an attractive target for malaria parasites because of their low immunological and behavioural defences, which are relatively immature at hatching [22, 23]. Development of the immune system begins posthatching and continues during the growth period, when birds are able to mount a significant immune response to blood parasites [24]. Therefore, age determines host cell maturation and the capacity to resist against parasites and support infections (reviewed in [25]). A naive immune system is known to increase susceptibility to parasitism and, therefore, those parasites that can take advantage of the immunologically naive hosts to increase its recruitment and survival rates should be favoured [25]. In birds, the immunological naive hosts (nestlings) are highly available to vectors only during early stages of development, whereas for much of the remaining year the host population consists of individuals with experience of prior infection. Moreover, infected nestlings may face at this stage a trade-off between allocating resources to growth or to keep them as immune enhancers for fighting parasites or diseases [26-29]. Thus, adults and nestlings should be considered altogether in order to better understand how parasites (in terms of species composition and prevalence) impact globally on a population. Despite its importance, surprisingly little is known about the avian malaria infections during the crucial phase of nestling growth as compared to adult phase.

Furthermore, parasite prevalence in vertebrates is often different between males and females [30,31], which has been mainly attributed to sex-specific host characteristics, such as the endocrine-immune interactions. Mounting evidence indicates that sex hormones influence the immune system [32-34]. Androgens, primarily testosterone, can suppress cell-mediated and humoral immunity in males, whereas oestrogen can suppress cell-mediated immunity while boosting humoral immunity in females [32]. In birds, evidence suggests that an effective immune system is costly, and that there are trade-offs among investment in immune function and other physiological and ecological aspects during reproduction [35-37]. This may result in differences in parasite prevalence between the sexes $[4,38]$. There is, therefore, a need to assess what role, if any, sex-related trade-offs between investment in immunity and other aspects of reproduction play in mediating acquisition of parasites, and if costs of parasite infections are different for each sex.

In this study, nestling and adults from a wild population of the open-ground nestling passerine Tawny pipit (Anthus campestris) were used as a novel host-parasite system to explore: (1) how malaria parasites are distributed among adults and nestlings, (2) the influence of the host sex on parasite prevalence in both groups of age, and (3) the association of parasite prevalence with adult body condition and nestling growth.

\section{Methods}

\section{Ethical consideration}

All research was carried out within Spanish standard requirements (project license reference JCCM/PAC 06-137) and the guidelines of the University of Castilla-La Mancha (CCM). All methods were approved by the University of Castilla-La Mancha ethical committee for Animal experimentation (CEEA) and permission to capture and manipulate birds was obtained from the Organismo Autonomo de Espacios Naturales de Castilla-La Mancha (permission numbers: OAEN/SVSIA/avp_10_153, and DGPF/08031701). Birds were caught under Spanish standard requirements (bird ringing license numbers: SEO/BirdLife 520038 and 530351).

\section{Host species, study areas and sampling method}

The Tawny pipit is a small ( 28 g) migratory passerine of the family Motacillidae. It is a widespread summer visitor of open habitats throughout Eurasia [39]. Tawny pipits are sexually monomorphic, with slightly larger males than females (mean $\pm \mathrm{SD}$; wing length $94.0 \pm 3.42$ and $88.0 \pm 2.32 \mathrm{~mm}$ for males and females, respectively; [39]). Males and females have different roles during breeding; while nest attendance and care for nestlings are exclusive to females, males are responsible for territory defence [40]. The open-cup nests are constructed directly on the ground [41]. Clutch size varies between three and five eggs, and nestlings are altricial (range time in the nest between 8 and 11 days) [40].

The study was conducted during the reproductive seasons of 2008, 2009, and 2010 in a study area with approximately $2.5 \mathrm{~km}^{2}$ located in Valeria, central Spain (Cuenca province, $39^{\circ} 48^{\prime} \mathrm{N}, 2^{\circ} 10^{\prime} \mathrm{W}, 1090 \mathrm{~m}$ above sea level). The 
study site is located in a flat terrain, where the species' density is about 15 breeding pairs $/ \mathrm{km}^{2}$. Climate is Mediterranean (annual rainfall is $750 \mathrm{~mm}$ and mean annual temperature $16^{\circ} \mathrm{C}$ ) and the prevailing habitat consists on natural shrub steppe vegetation (Rosmarinus officinalis, Thymus spp. and pastures dominated by Brachypodium phoenicoides) with scattered cereal crops.

Nest visits were performed at intervals of 3-5 days throughout the breeding season (May-July). A total of 105 adult birds were captured in their territory around nests (males, $n=63$ ) or at nest when feeding nestlings (females, $n=42$ ). Adults were measured (wing length and mass), ringed with a metal ring to avoid resampling, and $5-10 \mu \mathrm{l}$ of blood was collected from the jugular vein. Additionally, 95 nestlings ( 48 males and 47 females) from 28 nests were sampled twice at nest, when they were 1-3 day-old and when they were 7-11 day-old. During the first visit, all nestlings were marked with different waterproof colours on tarsus and feet to allow individual recognition. Wing length was measured with a ruler (accuracy $0.5 \mathrm{~mm}$ ) and body mass with a digital balance (accuracy $0.01 \mathrm{~g}$ ) in the two visits. During the last visit all nestlings were banded with a metal ring and 2-5 $\mu$ of blood was taken. Tawny pipits were classed in two age groups for analyses: adults ( $\geq 1$ year old) and nestlings (7-11 day old). Blood samples were preserved in ethanol until DNA analyses. All birds sampled were captured and handled with the corresponding permissions of both regional and national Spanish authorities.

\section{Genetic characterization of parasites}

DNA was extracted from blood samples using ammonium acetate/ethanol precipitation methods [7], and diluted to a working concentration of $25 \mathrm{ng} / \mu \mathrm{l}$. All birds were molecularly sexed by amplifying introns of the CHD1Z/W gene [42]. For the detection of parasites we used the nested polymerase chain reactions (PCR) protocol used by Waldenström [43], which amplify a fragment of the mitochondrial cytochrome $b$ gene of Plasmodium spp. and Haemoproteus spp. parasite genera. Each PCR included two positive samples of infected birds to verify the proper functioning of the reaction and a negative $\left(\mathrm{ddH}_{2} \mathrm{O}\right)$ to control for the presence of false positives. A volume of $2.5 \mu \mathrm{l}$ of each final reaction was evaluated on $2 \%$ agarose gels and stained with ethidium bromide. Pre- and post-PCR work was performed with different material and in different laboratory sections to avoid contamination. The protocol was repeated three times to confirm negative results. Samples with positive PCR reactions were cleaned up using Exonuclease I and Shrimp Alkaline Phospatase (Fermentas) and sequenced using the forward PCR primer and the Big Dye Terminator Kit (Applied Biosystems). DNA sequences were obtained using an ABI 3130XL Automated Sequencer (Applied Biosystems). Data were processed with the ABI PRISM1 Sequencing Analysis Software v3.7 (Applied Biosystems). New parasite lineages were sequenced twice to ensure the accuracy of the sequences.

\section{Phylogenetic analysis}

Sequences were edited manually using Bioedit 7.0.5.3 [44]. All new haplotypes were deposited in GenBank (accession numbers: JF279937-JF279958 and KF747759KF747764). The taxonomic identity of each haplotype was inferred by assessing the phylogenetic affinities with published sequences from GenBank that were reliably identified as morphological species of Plasmodium and Haemoproteus, as compiled in the MalAvi database [45]. Multiple infections (more than one parasite haplotype in the same individual) were identified by the presence of double peaks on the electropherograms [46]. Phylogenetic relationships among parasite haplotypes were estimated by Bayesian inference using MrBayes 3.1.2 [47]. The GTR+I+G model of molecular evolution was identified by jModelTest [48] as the most appropriate for the dataset. Two simultaneous runs of four Monte-Carlo Markov Chains (MCMC) were conducted over 5 million generations, sampled every 100 generations. The posterior probability distribution of the $50 \%$ majority rule consensus tree was calculated after discarding the first $25 \%$ generations as the burn-in period. The phylogenies were visualized using FigTree v1.3.1 [49].

The genetic divergence between different parasite haplotypes was calculated using the Tajima-Nei distance model computed in the software MEGA4 [50].

\section{Statistical analysis}

The effects of host sex and age on infection probability were analysed by means of generalized linear/nonlinear mixed models (GLMMs) with a binomial distribution for our dependent variable (infection status: infected or uninfected), and a logit link function. The model included year as random factor and age, sex, and their interaction as fixed effects. Date of sampling was incorporated as a continuous predictor to account for its possible effect on the infection probability. Date was calculated as the number of days from 1st April within each study year until the day of sampling. Individuals carrying multiple infections were treated as 'infected' in this analysis. Difference in the proportion of sexes and age cohorts infected by each parasite clade was tested using Fisher's exact test (two-tailed).

The effect of infection status on body condition was estimated for adults by means of linear mixed models (LMMs). The model included body mass as dependent variable and wing length as continuous predictor 
(to account for differences in size between individuals). Infection status (infected or uninfected), sex and their interaction were included as fixed factors. The model included also the year of study as a random factor and date of sampling as continuous predictor.

Additionally, we performed LMMs to investigate whether infection influence nestling growth (growth increments for mass and wing length) using the two measurements taken on each nestling during its nest stage. The rate of daily mass gain during growth was expressed as [(mass at second visit-mass at first visit)/ number of days between first and second visit], and the rate of daily wing length increment was expressed as [(wing length at second visit-wing length at first visit)/ number of days between first and second visit]. Two independent models were built, with mass gain or wing length increment as dependent variables, infection status (infected or uninfected), sex and their interaction as fixed factors, age of nestling and sampling date as continuous predictors, and year and nest identity as random factors.

All analyses were performed using R 2.14 [51] (R Core Team 2013). Specifically, package lme4 [52] was used to fit LMMs and GLMMs, and package phia [53] to perform post hoc analyses. Means and parameter estimates are reported together with their standard errors.

\section{Results}

In total, 92 out of the 200 birds screened were infected with malaria parasites, which represents an overall prevalence of $46 \%$ (Table 1). Multiple infections (3.3\%) and unresolved (poor-quality) sequences (2.2\%) were excluded from further analyses. Sequences from 86 Plasmodium (99 \%) and one Haemoproteus (1 \%) species were recorded, yielding 16 unique Plasmodium and one Haemoproteus cytochrome $b$ haplotypes. The most common parasite haplotype in Tawny pipits was BIC33 (31\%), followed by BIC39 (16.1\%), BIC8 (13.8\%), BIC29 (12.6\%) and BIC32 (11.5\%). Other haplotypes were detected at low rate (less than $3.0 \%$ of all infections). A Blast search (GenBank's basic alignment search tool) was performed for our cytochrome b haplotype dataset, identifying six Plasmodium haplotypes that had been previously recorded in other avian hosts: BIC29 (KF747759), BIC32 (KF747760), BIC33 (KF747761), BIC36 (KF747762), BIC37 (KF747763) and BIC39 (KF747764). The remaining 11 parasite haplotypes had not been previously described, and showed between 0.23 and $1.87 \%$ of genetic divergence with respect to any other Plasmodium or Haemoproteus lineage recorded, to date, in avian hosts.

\section{Clustering of parasite lineages}

The phylogenetic tree that resulted from Bayesian analyses is shown in Fig. 1. Morphospecies nomenclature was tentatively assigned to smaller cladistic groupings within the Plasmodium and Haemoproteus genera based on the affiliation and bootstrap support of branches with lineages published previously.

Five distinct Plasmodium clades (clades A-E; Fig. 1) were found, with genetic distances between haplotypes within clades ranging from 0.2 to $0.7 \%$ (mean $=0.44 \%$, S.D. $=0.2 \%$ ), whereas genetic divergence between these clades varies between 3.4 and $8.5 \%$ (mean difference $=6.4 \%$, S.D. $=2.1 \%$ ). Of the five clades, only two can be associated to a known parasite morphospecies (clade C: Plasmodium cathemerium, and clade B: Plasmodium relictum). One single Haemoproteus clade (clade F) was detected, which included only one haplotype isolated from Tawny Pipits (BIC15) that did not contain sequences of any of the Haemoproteus morphospecies previously described.

\section{Variation in parasite prevalence}

The prevalence of malaria infections in the Tawny pipit population studied did not show significant variation with date of sampling (Table 2). Overall, there were no significant differences between the infection status of the two age groups, being the proportion of infected adults and nestlings 0.45 and 0.46 , respectively (see also Table 1). However, Tawny pipit females have a lower

Table 1 Prevalence (in brackets) of malaria parasites in adult and nestling, male and female Tawny pipits from 2008 to 2010 in Valeria, Spain

\begin{tabular}{|c|c|c|c|c|c|c|c|c|}
\hline \multirow[t]{3}{*}{ Years } & \multicolumn{4}{|l|}{ Adults } & \multicolumn{4}{|l|}{ Nestlings } \\
\hline & \multicolumn{2}{|l|}{ Male } & \multicolumn{2}{|l|}{ Female } & \multicolumn{2}{|l|}{ Male } & \multicolumn{2}{|l|}{ Female } \\
\hline & Uninfected & Infected & Uninfected & Infected & Uninfected & Infected & Uninfected & Infected \\
\hline 2008 & 24 & $8(0.25)$ & 16 & $2(0.11)$ & 15 & $5(0.25)$ & 14 & $2(0.12)$ \\
\hline 2009 & 7 & $12(0.63)$ & 8 & $7(0.46)$ & 5 & $8(0.61)$ & 12 & $7(0.37)$ \\
\hline 2010 & 0 & $12(1.0)$ & 2 & $7(0.77)$ & 1 & $14(0.93)$ & 4 & $8(0.66)$ \\
\hline Total & 31 & $32(0.51)$ & 26 & $16(0.38)$ & 21 & $27(0.56)$ & 30 & $17(0.36)$ \\
\hline
\end{tabular}




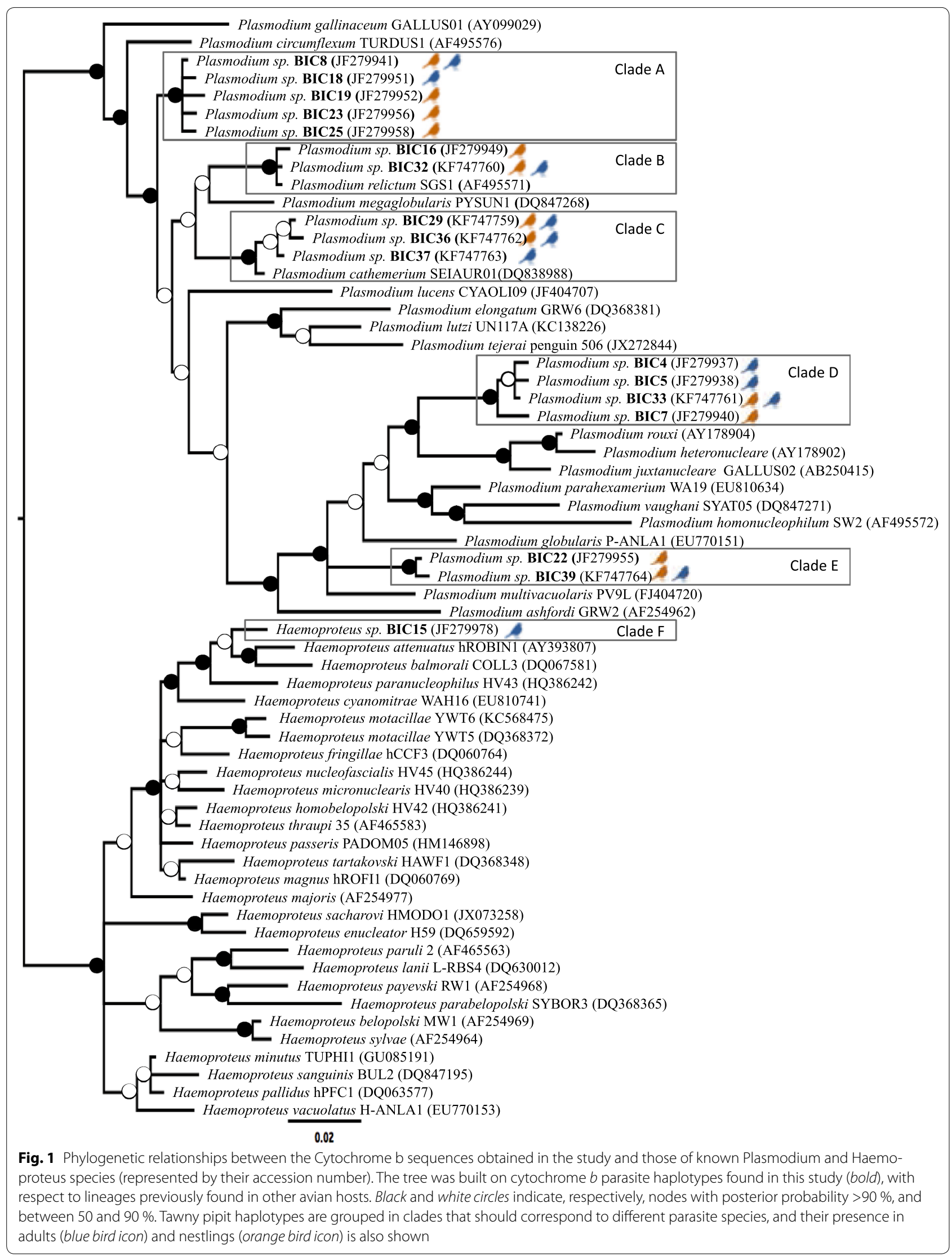


Table 2 Generalized linear mixed model estimates

\begin{tabular}{lrcc}
\hline Response variable & Estimate & Statistic value $(\mathbf{Z})$ & $\boldsymbol{P}$ value \\
\hline Sampling date & 0.02326 & 1.380 & 0.1665 \\
Age & -0.40358 & -0.778 & 0.4350 \\
Sex & 2.03322 & 2.130 & 0.0332 \\
Sex $\times$ age & -0.85431 & -0.793 & 0.4270 \\
\hline
\end{tabular}

Infected adult (age) and female (sex) served as a reference groups. Statistically significant results are shown in italics

prevalence of malaria than do males in the 3 years of study (Tables 1, 2). The proportion of infected females and males was 0.37 and 0.53 , respectively, and this pattern is consistent across ages, as supported by the nonsignificant interaction sex $\times$ age (Table 2 ).

At parasite-clade level, avian malaria clades A-E (see Fig. 1) found in our study area were all present in both adults and nestling, whereas clade F (Haemoproteus) was only retrieved from adults. The prevalence of clade A in Tawny pipits was $8.0 \%(n=200)$, with no significant differences between age classes (adults: $4.76 \%$, nestlings: $11.58 \%$; Fisher exact test, two tailed, $\mathrm{P}=0.11$ ). The prevalence of clade B was $5.5 \%$ (adults: $7.62 \%$, nestlings: $3.16 \%, \mathrm{P}=0.22$ ). The prevalence of clade $\mathrm{C}$ was $7.0 \%$ (adults: $10.48 \%$, nestlings: $3.16 \%, \mathrm{P}=0.053$ ) whereas the prevalence of clade D was $15 \%$ and similar between the two age classes $(16.19 \%$ in adults and $13.68 \%$ in nestlings, $\mathrm{P}=0.69)$. Finally, the prevalence of Clade $\mathrm{E}$ was $7.5 \%$ (adults: $4.76 \%$, nestlings: $10.53 \%, \mathrm{P}=0.18$ ).

There were significant differences between the prevalence of clades $B$ and $C$ according to sex, being both clades more frequent in males than in females (clade $B$ : males $12.0 \%$, females $1.12 \%$, Fisher exact test, two tailed, $\mathrm{P}=0.02$; clade C: males $9.0 \%$, females $1.12 \%, \mathrm{P}=0.02$ ). There were no statistical differences between males and females for clades A, D and E ( $\mathrm{P}>0.05)$.

\section{Infection status and body condition in adults}

Overall, body mass was positively related with wing length $(t=2.70, P=0.008)$, and was larger in males than in females $(t=1.94, P=0.055$; Fig. 2$)$. Infected individuals were in poorer condition than uninfected ones $(t=-2.91, P=0.004)$, and the significant interaction (infection $\times$ sex: $t=2.00, P=0.048$ ) indicates that the effect of infection status on body mass was significant for females (post hoc: $\chi_{1}^{2}=8.49, P=0.007$ ) but not for males $\left(\chi_{1}^{2}=0.23, P=0.63\right.$ ) (Fig. 2$)$. There was no support for a significant effect of date of sampling on body mass $(t=-0.78, P=0.44)$.

\section{Infection status and growth in nestlings}

Sex of nestlings accounted for most of the variation in daily mass gain, and this variation was statistically significant (daily body mass gain $=1.90 \pm 0.05 \mathrm{~g}$. for males and $1.72 \pm 0.05$ for females, $t=5.48, P<0.0001)$. Overall, infected nestlings gain weight at the same rate as uninfected ones $(t=-0.035, P=0.97)$. Interestingly, the interaction between sex and infection status is statistically significant $(t=-2.29, P=0.025)$ because infected males had a significant lower mass gain than uninfected males (post hoc: $\chi_{1}^{2}=7.23, P=0.014$ ) whereas females did not $\left(\chi_{1}^{2}=0.00, P=0.97\right.$, Fig. 3$)$. Neither age of nestling $(t=-1.38, \mathrm{df}=51.58, P=0.17)$ nor date of sampling $(t=-0.11, \mathrm{df}=21.34, P=0.91)$ was significantly related to daily mass gain.

Wing length increment was higher for males than for females (males: $5.18 \pm 0.08 \mathrm{~mm}$, females: $4.87 \pm 0.09$ for females, $t=3.52, P=0.0008$ ). Differences in wing length increment among infected and uninfected individuals were not significant $(t=1.03, P=0.31)$, and the interaction between sex and infection status was also not significant $(t=-0.51, P=0.61)$. Date of sampling was not significantly related to wing length increment $(t=0.07$, $P=0.97$, whereas age of nestling is marginally significant in the model $(t=-1.98, P=0.053)$.

\section{Discussion}

The present study adds data on host-parasite relationships for a so far non-investigated passerine species, the Tawny pipit. Host sex-related differences affecting prevalence of avian malaria, but no evidence of age-related differences, were reported here. Tawny pipit males were more likely to be infected by malaria parasites compared to females, and this sex-bias parasitism was evident in

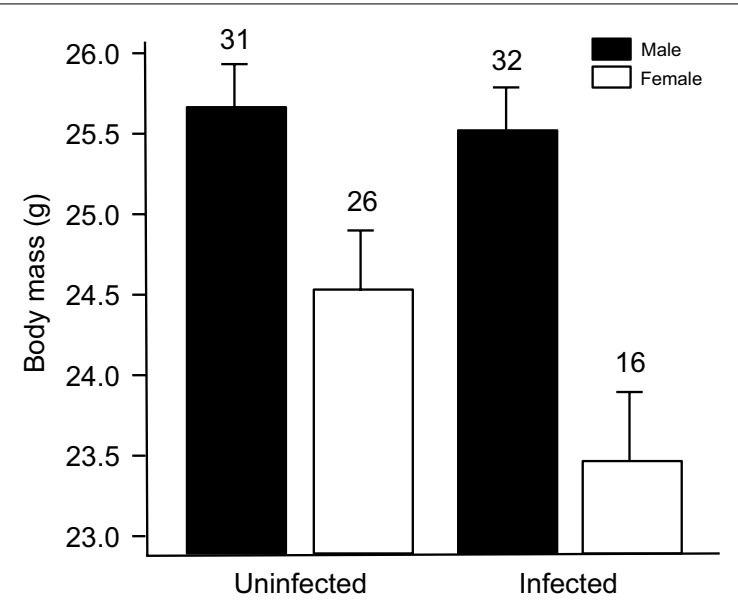

Fig. 2 Effects of avian malaria infections on adult body condition. Host adult body mass after controlling by wing length (fitted means + SE from the model, see "Methods" section). The figure shows the interaction between infection status and sex in the linear mixed model (see "Methods" section). Sample size indicated above error bars. Other variables in the model are described in "Results" section 


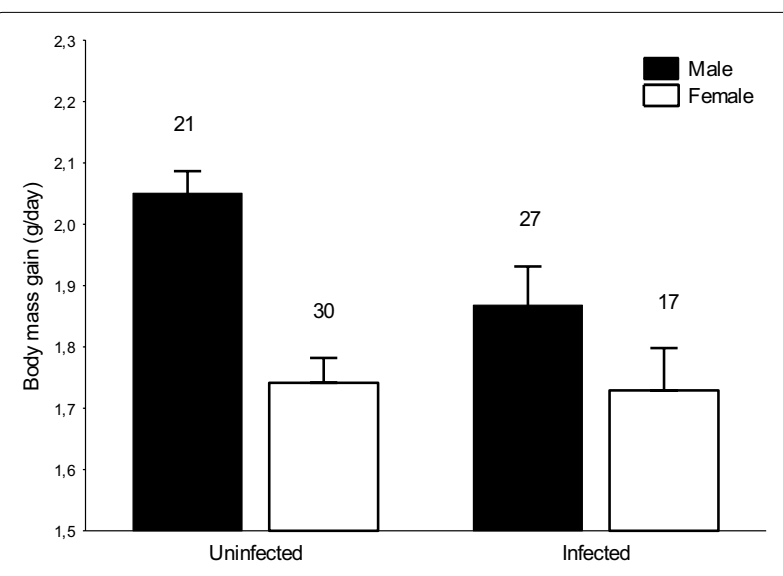

Fig. 3 Effects of avian malaria infections on nestling growth. Variation in body mass gain (grams per day) in relation to infection status and sex of nestlings. Data are expressed as fitted mean + SE from the model (see "Methods" section). Sample size indicated above error bars. Other variables in the model are described in "Results" section

both adults and nestlings. Avian malaria parasites were also prevalent in 7-11 day-old nestlings, consistent with other reports [54]. Most importantly, infected males showed lower daily mass gain during nestling growth than infected females, whereas infections at adulthood were associated with lower condition in females than in males.

The effect of host age on parasite prevalence is a controversial topic in avian ecology. On one hand, the number of host-parasite encounters and the accumulation of infections over time means that we can expect a pattern of higher parasite prevalence in adults than at early stages of life $[55,56]$. On the other hand, the low immunological and behavioural defences against parasites of nestlings compared to adults suggest the opposite pattern, with higher expected prevalence in nestlings than in adults $[57,58]$. Few studies have explicitly compared avian malaria infections between nestlings and adults in the wild, since the prepatent period (when the parasite is developing in the host tissues and absent from blood) is often longer than the nestling period of most bird species (see [59]). Results from Tawny pipit supported the hypothesis that the naïve immune system makes nestlings highly susceptible to developing infections. The agepattern of malaria infection found in this study indicated a rapid accumulation of parasites at the age at which an individual is first susceptible to infection. Considering the age of nestlings studied (7-11 days) and that prepatent periods for avian species of Plasmodium and Haemoproteus range from 2 days to several months [60], it is likely that some of the nestlings considered as uninfected in this study might be truly infected, but the disease has not yet reached the blood (prepatent stage) at the time of sampling. If so, the real parasite prevalence in nestlings can be underestimated, and the age-prevalence curve would reflect a decreasing incidence of malaria with age [58] typical of a parasite-mediated viability selection pattern [61, 62]. A reduction of prevalence with age should merely indicate the loss (death) of infected individuals from the population [58,61], or that parasites were cleared from hosts or entered a latent stage (remaining usually in host tissues) later in life [63, 64]. Unfortunately discrimination among these possibilities is not possible in the present study, but the topic merits further research as they can reveal patterns that may allow quantification of rates of parasite transmission, parasite-induced host mortality, and development of host resistance.

Regarding the processes whereby infections occur, age-specific differences in physiological trade-offs would explain, at least in part, the observed pattern [58]. Nestlings hatch when parasite prevalence peaks in vector populations $[65,66]$, so they are expected to rapidly acquire numerous parasite lineages present in the breeding area. Maturation of the immune system in birds may take several weeks after hatching and, therefore, investment in immune defence may come at the expense of investment in somatic growth (review in [67]), which may be especially patent for species with determinate growth (i.e. growth ceases before chicks leave the nest) like passerines. Moreover, in species or populations at higher risk of nest predation the trade-off between investment in immune defence and investment in growth may be particularly important, as predation is one ecological factor that exerts strong selection on growth rates in passerines $[68,69]$. Ground-nesting species living in open environments in the Mediterranean region are under strong predation rates [40,70], and previous work conducted on the same Tawny pipit population has shown that nest predation is a key factor driving the species' reproduction [40]. As a consequence, nestlings of altricial or semi-altricial species, such as Tawny pipits, should reach adult size faster than precocial species [71], indicating that growth is compressed into a shorter period fuelled by a strong evolutionary pressure to leave the nest as soon as possible in order to avoid or minimize predation [72]. Therefore, nestlings may prioritize growth over development of immune function, causing high disease incidence in this age group despite the short time of exposure to parasites. The high prevalence found in nestlings, together with the fact that most parasite haplotypes were found infecting both nestlings and adults points towards transmission of these parasites in the European breeding grounds of Tawny pipits. The only exception was the Haemoproteus haplotype, which was detected only in adults. This suggest that parasites of this clade could have been transmitted in winter quarters (i.e. Africa), as proposed in 
the case of many other Haemoproteus and Plasmodium haplotypes for which the occurrence of suitable vectors in Europe could be currently absent [73]. Alternatively, perhaps, the prepatent period for Haemoproteus spp. described in the literature (between 11 days and 3 weeks) diminishes the probability of detection in the nestling age cohort.

Differences between males and females in prevalence and/or intensity of infection, in particular male-biased parasitic infections, are often observed in nature $[6,31$, $35,74-76]$. However, sex-bias in parasitism is not universal and consistent, and often varies between and within host-parasite systems [3, 58, 77]. In Tawny pipits, males had higher parasite prevalence than females in both age cohorts, a pattern compatible with gender differences in susceptibility to parasites according to biological differences between host sexes [78]. In the avian malaria system, host sex is considered as a potentially important source of variation in both prevalence and cost of parasites for hosts [78]. The proximate explanations for sex-bias in parasitism may be caused by many different factors that revolve around two hypotheses, which are not mutually exclusive: 1) certain hormones have an immunosuppressive effect upon the host defence against pathogens, and 2) because of morphological and/ or behavioural differences, one sex has a greater likelihood of being parasitized by differential exposure to vectors $[35,79]$. In Tawny pipits, males and females do not differ substantially in mass or colour [80] and their home ranges overlap within territories, which were probably not large enough (3.5-12.1 ha; [81]) to explain differences in vector exposure between males and females. Although behavioural differences cannot be excluded as a potential explanation, there is overwhelming evidence that sex-associated hormones can directly influence the susceptibility of each sex to infections [35]. For example, testosterone has immunosuppressive effects in some species, leading to increased susceptibility of males to parasite infections [82]. However, while the immunosuppressive effect of sex-linked hormones is a well-recognized phenomenon in adulthood [83, 84], that could explain the results found in adults, its rationale in the case of nestlings is not clear, as differences in susceptibility to parasite infection might not be attributable directly to sexual differences in circulating testosterone levels [85]. Firm conclusions cannot be drawn about why males were more infected than female nestlings, but the results found on differential growth between sexes (discussed below) should shed some light on this issue.

Male and female nestlings leave the nest at the same time; therefore, for a species where males are slighter larger in wing size than females [80], males may need to grow faster than their smaller sisters, as supported by the higher wing growth rate of male nestling compared to females found in this study. The growth strategy of small breeding-ground passerines under strong nest-predation rates may be due to the need to leave the nest as soon as possible, which depends on their ability to fly and, thus, the development of the wings. If male nestlings need to allocate more resources to growth and less to prevent infections than females this could result in increased parasite prevalence in males as compared to females. In a comparative study with amphibians, Johnson et al. [86] showed that amphibian species with rapid growth were more susceptible to infections and pathology than species with slow growth. Within birds, selection for growth compromises the immune function in lines of commercial poultry (meta-analysed by van der Most et al. [87]). Although the increment in wing length was higher for male than for female nestlings, wing-growth strategies in both sexes seem to be unaffected by parasite infections. As a faster development of wings can facilitate both escape from predators and survival outside the nest, growth of body components that reduces the risk of predation may be relatively prioritized over mass in species at higher risk of nestling predation [71]. In contrast, there is a clear sex-biased growth strategy in relation to the rate at which individuals gain body mass under malaria infestation. The advantage of 'being a male'-attaining higher weight and larger biometric size than sisters-, and the competitive strength related to this [88] becomes a handicap under parasite infestation, when the selective pressure for a faster growth is strong. In our study, the impact of parasites in term of mass gain is particularly important in the fastest growing sex [89], which support this idea. Unfortunately, the potential incidence of a reduced condition during growth on posterior mortality rates cannot be evaluated here, but several authors have demonstrated this kind of relationships [90, 91]. Therefore, in species/ populations that evolved under strong (nest) predation pressures, such as Tawny pipits [40], the impact of malaria parasites might ultimately influence offspring mortality rates.

Once adulthood is reached, selection pressures changed, and the trade-offs between immune system and investment in reproduction makes females more susceptible to the effect of malaria parasites than males. In our species model, females make greater investment than males in terms of time and energy during breeding, since females are solely responsible for incubation and chick rearing, which included the search for food and feeding chicks [40]. As a result, Tawny pipit females show a continuous decline in body condition during the breeding season of around $27 \%$ of initial mass [92]. Here, infection was associated to a reduced host condition for females but not for males, supporting the view 
that infections by malaria parasites cause sex-related differences in host body condition, presumably as a result of increased investment in reproduction by females compared to males. However, it is also possible that host with reduced body mass may be less likely to fight off parasites or their vectors. Further work is clearly needed to conclusively evaluate the link between reproductive effort in both sexes and the effect of parasites acquired by Tawny pipits.

\section{Conclusions}

Most studies only consider adults when investigating avian malaria parasites and as a result infection in nestlings is under-represented in the literature. This study has focussed not only in adults (in terms of parasite prevalence and association with body condition), but also considered infections of these parasites in nestlings (prevalence and effects on nestling growth). This study has demonstrated high prevalence of avian malaria parasites in nestlings (7-11 day-old), comparable to adult prevalence, and sex-related differences in both age groups. Both the acquisition of these parasites as well as the consequences of parasites for individuals depends on host sex and age. Trade-offs between investment in immune system and investment in other tasks (reproduction in adults and growth in nestlings) may explain the results found, and some ecological factors (nest predation) could exacerbate the effects of malaria parasites for avian hosts at the population level.

\section{Authors' contributions}

MC-R and JTG conceived and designed the study, analysed data and wrote the manuscript. MC-R collected data and performed molecular analyses under the supervision of JTG. Both authors read and approved the final manuscript.

\begin{abstract}
Acknowledgements
The authors acknowledge the infrastructural support of the Institute of Research in Game Resources (IREC), the Spanish National Research Council (CSIC), and the University of Castilla-La Mancha (UCLM). This study was funded by Junta de Comunidades de Castilla-La Mancha (PAC06-0137 and PII1C090128-4724) and CSIC (PIE 201030I019). MC-R was funded by an I3P grant from CSIC. Thanks are also due to J.C.C.M. committee for approval the protocols (Refs: OAEN/SVSIA/avp_10_153 and DGPF/08031701). The fieldwork has been possible thanks to the permission and cooperation of the landowners of Valeria. We thank F. Alda for a critical reading of an earlier draft of this manuscript and stimulating suggestions. Comments from C. Ferreira and P. Cabezas and one anonymous reviewer greatly improved this manuscript.
\end{abstract}

\section{Competing interests}

The authors declare that they have no competing interests.

Received: 1 October 2015 Accepted: 9 March 2016

Published online: 22 March 2016

\section{References}

1. Hudson P, Rizzoli A, Grenfell B, Heesterbeek H, Dobson A. The ecology of wildlife diseases. Oxford: Oxford University Press; 2002.
2. Gourbière $S$, Morand S, Waxman D. Fundamental factors determining the nature of parasite aggregation in hosts. PLoS One. 2015;10:e0116893.

3. Korpimäki E, Hakkarainen H, Bennett G. Blood parasites and reproductive success of Tengmalm's owls: detrimental effects on females but not on males? Funct Ecol. 1993;7:420-6.

4. Sheldon B, Verhulst S. Ecological immunology: costly parasite defences and trade-offs in evolutionary ecology. Trends Ecol Evol. 1996;11:317-21.

5. Knowles SCL, Nakagawa S, Sheldon BC. Elevated reproductive effort increases blood parasitaemia and decreases immune function in birds: a meta-regression approach. Funct Ecol. 2009;23:405-15.

6. Zuk M, Stoehr AM. Sex differences in susceptibility to infection: an evolutionary perspective. In: Klein SL, Roberts CW, editors. Sex hormones and immunity to infection. Berlin: Springer; 2010. p. 1-17.

7. Isaksson C, Sepil I, Baramidze V, Sheldon BC. Explaining variance of avian malaria infection in the wild: the importance of host density, habitat, individual life-history and oxidative stress. BMC Ecol. 2013;13:15.

8. Ricklefs RE, Fallon SM, Bermingham E. Evolutionary relationships, cospeciation, and host switching in avian malaria parasites. Syst Biol. 2004;53:111-9.

9. Atkinson C, van Riper III C. Pathogenicity and epizootiology of avian haematozoa: Plasmodium, Leucocytozoon, and Haemoproteus. In: Loye E, Zuk M, editors. Bird-parasite interactions: ecology, evolution, and behaviour. Oxford: Oxford University Press; 1991. p. 19.

10. Allander K, Bennett $G$. Retardation of breeding onset in Great tits (Parus major) by blood parasites. Funct Ecol. 1995;9:677-82.

11. Oppliger A, Christe P, Richner H. Clutch size and malarial parasites in female great tits. Behav Ecol. 1997;8:148.

12. Bennett GF, Caines JR, Bishop MA. Influence of blood parasites on the body mass of passeriform birds. J Wildl Dis. 1988;24:339-43.

13. Nordling D, Andersson M, Zohari S, Gustafsson L. Reproductive effort reduces specific immune response and parasite resistance. Proc $\mathrm{R}$ Soc $B$ Biol Sci. 1998;265:1291.

14. Merino S, Moreno J, Sanz J, Arriero E. Are avian blood parasites pathogenic in the wild? A medication experiment in blue tits (Parus caeruleus). Proc R Soc B Biol Sci. 2000;267:2507.

15. Marzal A, Lope F, Navarro C, Müller A. Malarial parasites decrease reproductive success: an experimental study in a passerine bird. Oecologia. 2005; 142:541-5.

16. Lachish S, Knowles SC, Alves R, Wood MJ, Sheldon BC. Infection dynamics of endemic malaria in a wild bird population: parasite species-dependent drivers of spatial and temporal variation in transmission rates. J Anim Ecol. 2011:80:1207-16.

17. Asghar M, Hasselquist D, Hansson B, Zehtindjiev P, Westerdahl H, Bensch S. Hidden costs of infection: chronic malaria accelerates telomere degradation and senescence in wild birds. Science. 2015;347:436-8.

18. Van Riper III C, van Riper S, Goff M, Laird M. The epizootiology and ecological significance of malaria in Hawaiian land birds. Ecol Monogr. 1986:56:327-44.

19. Bennett G. Phylogenetic distribution and possible evolution of the avian species of the Haemoproteidae. Syst Parasitol. 1993;26:39-44.

20. Weatherhead PJ, Bennett GF. Ecology of parasitism of brown-headed cowbirds by haematozoa. Can J Zool. 1992;70:1-7.

21. Atkinson CT, Dusek RJ, Woods KL, Iko WM. Pathogenicity of avian malaria in experimentally-infected Hawaii amakihi. J Wildl Dis. 2000;36:197-204.

22. Apanius V. Stress and immune defense. Adv Study Behav. 1998;27:133-53.

23. Pastoret P-P, Griebel P, Bazin H, Govaerts A. Handbook of vertebrate immunology. London: Academic Press Limited; 1998.

24. Atkinson CT, Dusek RJ, Lease JK. Serological responses and immunity to superinfection with avian malaria in experimentally-infected Hawaii amakihi. J Wildl Dis. 2001;37:20-7.

25. Merino S. Immunocompetence and parasitism in nestlings from wild populations. Open Ornithol J. 2010;3:27-32.

26. Soler JJ, de Neve L, Pérez-Contreras T, Soler M, Sorci G. Trade-off between immunocompetence and growth in magpies: an experimental study. Proc R Soc Lond B Biol Sci. 2003;270:241-8.

27. Brommer J. Immunocompetence and its costs during development: an experimental study in blue tit nestlings. Proc R Soc Lond B Biol Sci. 2004:271:S110.

28. Grindstaff JL. Maternal antibodies reduce costs of an immune response during development. J Exp Biol. 2008;211:654-60 
29. Moreno J, Lobato E, Morales J, Merino S, Martínez-De La Puente J, Tomás G. Pre-laying nutrition mediates maternal effects on offspring immune capacity and growth in the pied flycatcher. Oecologia. 2008;156:727-35.

30. Zuk M, McKean K. Sex differences in parasite infections: patterns and processes. Int J Parasitol. 1996;26:1009-24.

31. Schalk G, Forbes MR. Male biases in parasitism of mammals: effects of study type, host age, and parasite taxon. Oikos. 1997;78:67-74.

32. Grossman CJ. Interactions between the gonadal steroids and the immune system. Science. 1985;227:257-61.

33. Grossman C. Possible underlying mechanisms of sexual dimorphism in the immune response, fact and hypothesis. J Steroid Biochem. 1989;34:241-51.

34. Schuurs A, Verheul H. Effects of gender and sex steroids on the immune response. J Steroid Biochem. 1990;35:157-72.

35. Folstad I, Karter A. Parasites, bright males, and the immunocompetence handicap. Am Nat. 1992;139:603-22.

36. Ots I, Horak P. Great tits Parus major trade health for reproduction. Proc R Soc Lond B Biol Sci. 1996;263:1443-7.

37. Deviche P, Parris J, Hobson K. Testosterone treatment to free-ranging male dark-eyed juncos (Junco hyemalis) exacerbates hemoparasitic infection. Auk. 2006;123:548-62.

38. Dawson RD, Bortolotti GR. Sex-specific associations between reproductive output and hematozoan parasites of American kestrels. Oecologia. 2001;126:193-200.

39. Alström P, Mild K. Pipits and Wagtails of Europe, Asia and North America: identification and systematics. London: Christopher Helm Publishers; 2003.

40. Calero-Riestra M, García JT, Herranz J, Suárez F. Breeding output and nest predation patterns in steppe-associated Mediterranean birds: the case of the Tawny Pipit Anthus campestris. J Ornithol. 2013;154:289-98.

41. Högstedt G. Orientation of the entrance in Tawny Pipit Anthus campestris nests. Ornis Scand. 1978;9:193-6.

42. Round PD, Hansson B, Pearson DJ, Kennerley PR, Bensch S. Lost and found: the enigmatic large-billed reed warbler (Acrocephalus orinus) rediscovered after 139 years. J Avian Biol. 2007;38:133-8.

43. Waldenström J, Bensch S, Hasselquist D, Östman Ö. A new nested polymerase chain reaction method very efficient in detecting Plasmodium and Haemoproteus infections from avian blood. J Parasitol. 2004;90:191-4.

44. Hall TA. BioEdit: a user-friendly biological sequence alignment editor and analysis program for Windows 95/98/NT. Nuc Acids Symp Ser. 1999;41:95-8

45. Bensch S, Hellgren O, Pérez-Tris J. MalAvi: a public database of malaria parasites and related haemosporidians in avian hosts based on mitochondrial cytochrome b lineages. Mol Ecol Resour. 2009;9:1353-8.

46. Perez-Tris J, Bensch S. Diagnosing genetically diverse avian malarial infections using mixed-sequence analysis and TA-cloning. Parasitology. 2005:131:15-23.

47. Ronquist F, Huelsenbeck J. MrBayes 3: Bayesian phylogenetic inference under mixed models. Bioinformatics. 2003;19:1572.

48. Posada D. jModelTest: phylogenetic model averaging. Mol Biol Evol. 2008;25:1253-6.

49. Rambaut A. FigTree: tree figure drawing tool, version 1.4.0. http://tree.bio. ed.ac.uk/software/figtree/.

50. Tamura K, Dudley J, Nei M, Kumar S. MEGA4: molecular evolutionary genetics analysis (MEGA) software version 4.0. Mol Biol Evol. 2007;24:1596.

51. The $R$ team. $R$ : a language and environment for statistical computing. $R$ foundation for statistical computing, Vienna, Austria; 2008.

52. Bates D, Mächler M, Bolker B, Walker S. Ime4: Linear mixed-effects models using Eigen and S4. R package version 1.0-4; 2013.

53. De Rosario-Martinez H. Phia: Post-hoc interaction analysis. R package version 01-3, 2013.

54. Zehtindjiev P, Križanauskienė A, Scebba S, Dimitrov D, Valkiūnas G, Hegemann A, et al. Haemosporidian infections in skylarks (Alauda arvensis): a comparative PCR-based and microscopy study on the parasite diversity and prevalence in southern Italy and The Netherlands. Eur J WildI Res. 2012;58:335-44

55. Dobson A, Hudson P. Microparasites: observed patterns in wild animal populations. In: Grenfell BT, Dobson AP, editors. Ecology of infectious diseases in natural populations. Cambridge: Cambridge University Press; 1995. p. 52-89.

56. Deviche P, McGraw K, Greiner E. Interspecific differences in hematozoan infection in Sonoran Desert Aimophila sparrows. J Wildl Dis. 2005;41:532.

57. Hudson P, Dobson A. Host-parasite Processes and Demographic Consequences. In: Clayton DH, Moore J, editors. Host-parasite evolution: general principles and avian models. Oxford: Oxford University Press; 1997. p. 128-54.

58. Van Oers K, Richardson D, Sæther S, Komdeur J. Reduced blood parasite prevalence with age in the Seychelles warbler: selective mortality or suppression of infection? J Ornithol. 2010;151:69-77.

59. Cosgrove CL, Knowles SCL, Day KP, Sheldon BC. No evidence for avian malaria infection during the nestling phase in a passerine bird. J Parasitol. 2006;92:1302-4

60. Valkiunas G. Avian malaria parasites and other haemosporidia. Florida: CRC Press; 2005

61. Sol D, Jovani R, Torres J. Parasite mediated mortality and host immune response explain age-related differences in blood parasitism in birds. Oecologia. 2003;135:542-7.

62. Wood E, Matthews J, Stephenson S, Slote M, Nussey D. Variation in fecal egg counts in horses managed for conservation purposes: individual egg shedding consistency, age effects and seasonal variation. Parasitology. 2013;140:115-28.

63. Jarvi SI, Schultz JJ, Atkinson CT. PCR diagnostics underestimate the prevalence of avian malaria (Plasmodium relictum) in experimentally-infected passerines. J Parasitol. 2002;88:153-8.

64. Jarvi S, Farias M, Baker H, Freifeld H, Baker P, Van Gelder E, et al. Detection of avian malaria (Plasmodium spp.) in native land birds of American Samoa. Conserv Genet. 2003:4:629-37.

65. Beaudoin R, Applegate J, Davis D, McLean R. A model for the ecology of avian malaria. J Wildl Dis. 1971;7:5-13.

66. Cosgrove CL, Wood MJ, Day KP, Sheldon BC. Seasonal variation in Plasmodium prevalence in a population of blue tits Cyanistes caeruleus. J Anim Ecol. 2008;77:540-8

67. Moller AP, Arriero E, Lobato E, Merino S. A meta-analysis of parasite virulence in nestling birds. Biol Rev. 2009;84:567-88.

68. Remeš V, Martin TE. Environmental influences on the evolution of growth and developmental rates in passerines. Evolution. 2002;56:2505-18.

69. Martin TE, Lloyd P, Bosque C, Barton DC, Biancucci AL, Cheng Y, et al. Growth rate variation among passerine species in tropical and temperate sites: an antagonistic interaction between parental food provisioning and nest predation risk. Evolution. 2011;65:1607-22.

70. Yanes M, Suarez F. Nest predation patterns in ground-nesting passerines on the Iberian Peninsula. Ecography. 1995;18:423-8.

71. Cheng Y-R, Martin TE. Nest predation risk and growth strategies of passerine species: grow fast or develop traits to escape risk? Am Nat. 2012;180:285-95

72. Bosque C, Bosque MT. Nest predation as a selective factor in the evolution of developmental rates in altricial birds. Am Nat. 1995;145:234-60.

73. Hellgren O, Waldenström J, Pérez-Tris J, Szöll E, Si O, Hasselquist D, et al. Detecting shifts of transmission areas in avian blood parasites: a phylogenetic approach. Mol Ecol. 2007;16:1281-90.

74. Poulin R. Sexual inequalities in helminth infections: a cost of being a male? Am Nat. 1996;147:287-95

75. Skorping A, Jensen KH. Disease dynamics: all caused by males? Trends Ecol Evol. 2004;19:219-20.

76. Nunn CL, Altizer S. Infectious diseases in primates: behavior, ecology and evolution. Oxford: Oxford University Press; 2006.

77. Wood MJ, Cosgrove CL, Wilkin TA, Knowles SCL, Day KP, Sheldon BC. Within-population variation in prevalence and lineage distribution of avian malaria in blue tits, Cyanistes caeruleus. Mol Ecol. 2007;16:3263-73.

78. McCurdy D, Shutler D, Mullie A, Forbes M. Sex-biased parasitism of avian hosts: relations to blood parasite taxon and mating system. Oikos. 1998;82:303-12.

79. Zuk M. Reproductive strategies and disease susceptibility: an evolutionary viewpoint. Parasitol Today. 1990;6:231-3.

80. Mild K, Alstrom P. Pipits and Wagtails of Europe, Asia and North America. London: A\&C Black; 2010.

81. Bijlsma R. Habitat, territoriumgrootte en broedsucces van Duinpiepers Anthus campestris. Limosa. 1990;63:80-1. 
82. Hillgarth N, Wingfield JC. Testosterone and immunosuppression in vertebrates: implications for parasite-mediated sexual selection. In: Beckage NE, editor. Parasites and pathogens: effects on host hormones and behavior. New York: Chapman \& Hall; 1997. p. 143-55.

83. Owen-Ashley NT, Hasselquist D, Wingfield JC. Androgens and the immunocompetence handicap hypothesis: unraveling direct and indirect pathways of immunosuppression in song sparrows. Am Nat. 2004;164:490-505.

84. Mougeot F, Redpath SM, Piertney SB. Elevated spring testosterone increases parasite intensity in male red grouse. Behav Ecol. 2006;17:117-25

85. Fargallo JA, Martínez-Padilla J, Toledano-Díaz A, Santiago-Moreno J, Davila JA. Sex and testosterone effects on growth, immunity and melanin coloration of nestling Eurasian kestrels. J Anim Ecol. 2007;76:201-9.

86. Johnson PT, Rohr JR, Hoverman JT, Kellermanns E, Bowerman J, Lunde KB. Living fast and dying of infection: host life history drives interspecific variation in infection and disease risk. Ecol Lett. 2012;15:235-42.
87. Van der Most PJ, de Jong B, Parmentier HK, Verhulst S. Trade-off between growth and immune function: a meta-analysis of selection experiments. Funct Ecol. 2011;25:74-80.

88. Oddie KR. Size matters: competition between male and female great tit offspring. J Anim Ecol. 2000;69:903-12.

89. Szép T, Møller A. Cost of parasitism and host immune defence in the sand martin Riparia riparia: a role for parent-offspring conflict? Oecologia. 1999;119:9-15.

90. Gebhardt-Henrich S, Richner H. Causes of growth variation and its consequences for fitness. Oxf Ornithol Ser. 1998;8:324-39.

91. Fitze PS, Clobert J, Richner H. Long-term life-history consequences of ectoparasite-modulated growth and development. Ecology. 2004;85:2018-26

92. Suarez F, Traba J, Herranz J. Body mass changes in female tawny pipits Anthus campestris during the nesting stage. J Ornithol. 2005;146:372-6.

\section{Submit your next manuscript to BioMed Central} and we will help you at every step:

- We accept pre-submission inquiries

- Our selector tool helps you to find the most relevant journal

- We provide round the clock customer support

- Convenient online submission

- Thorough peer review

- Inclusion in PubMed and all major indexing services

- Maximum visibility for your research

Submit your manuscript at www.biomedcentral.com/submit
(O) BioMed Central 